\title{
Osteomielite Enfisematosa
}

\section{Emphysematous Osteomyelitis}

Andreia Machado Ribeiro (https://orcid.org/0000-0002-0203-5536), Joana Tavares Pereira (https://orcid.org/0000-00021424-3746), Carla Tonel (https://orcid.org/0000-0001-6325-3206), José Barata (https://orcid.org/0000-0003-1300-3051)

Palavras-chave: Enfisema; Escherichia coli; Osteomielite.

Keywords: Emphysema; Escherichia coli; Osteomyelitis.

A osteomielite enfisematosa (OE) caracteriza-se pela presença intraóssea de gás. A via de infeção mais comum é hematogénea, sendo as Enterobacteriaceae e os anaeróbios os agentes mais frequentes. ${ }^{1,2}$

Homem de 70 anos, com antecedentes de neoplasia da próstata com metastização ganglionar e óssea; hipertensão arterial e diabetes mellitus tipo 2. Recorreu ao hospital por febre após realização de sessão de quimioterapia. Apresentava-se hipertenso, taquicárdico e com desconforto à palpação do hipogastro. Analiticamente, leucocitose 21200 com neutofilia 97\%; creatinina 2,6 mg/dL; PCR 57,1 mg/ dL; hiperglicémia 500 mg/dL, urina com leucocitúria $500 / \mu \mathrm{L}$ e nitritos positivos. A ecografia renal revelou uretero-hidronefrose esquerda e espessamento do urotélio por provável infeção associada. Ficou internado com o diagnóstico de infeção urinária e iniciou ceftriaxone.

A urocultura e hemoculturas identificaram Escherichia coli sensível ao trimetropim/sulfametoxazol pelo que a antibioterapia foi alterada. A tomografia computorizada (TC) abdominopélvica mostrou extensas alterações ósseas no sacro, com múltiplos pequenos focos de ar intramedular à direita, suspeito de osteomielite enfisematosa (Fig.s 1 e 2); próstata com nodularidade; marcada ureterohidronefrose crónica esquerda devido a massa adenopática tumoral ilíaca. A Ortopedia excluiu indicação cirúrgica.

Cumpriu 28 dias de antibioterapia, tendo-se verificado melhoria clínica e analítica progressiva. Teve alta com indicação para manter antibioterapia durante mais 4 semanas.

Os doentes diabéticos são mais suscetíveis ao desenvolvimento de OE e têm maior risco de complicações. ${ }^{3,4}$

A TC é o método de diagnóstico mais sensível., ${ }^{3,5} \mathrm{O}$ tratamento inclui antibioterapia dirigida ao agente etiológico, embora ainda não exista consenso quanto à duração pensa-se que 4 a 6 semanas serão adequadas. ${ }^{3} \mathrm{O}$ desbridamento

Serviço de Medicina Interna, Hospital Vila Franca de Xira, Vila Franca de Xira, Portugal.

DOI: 10.24950/rspmi.i.189.4.2021

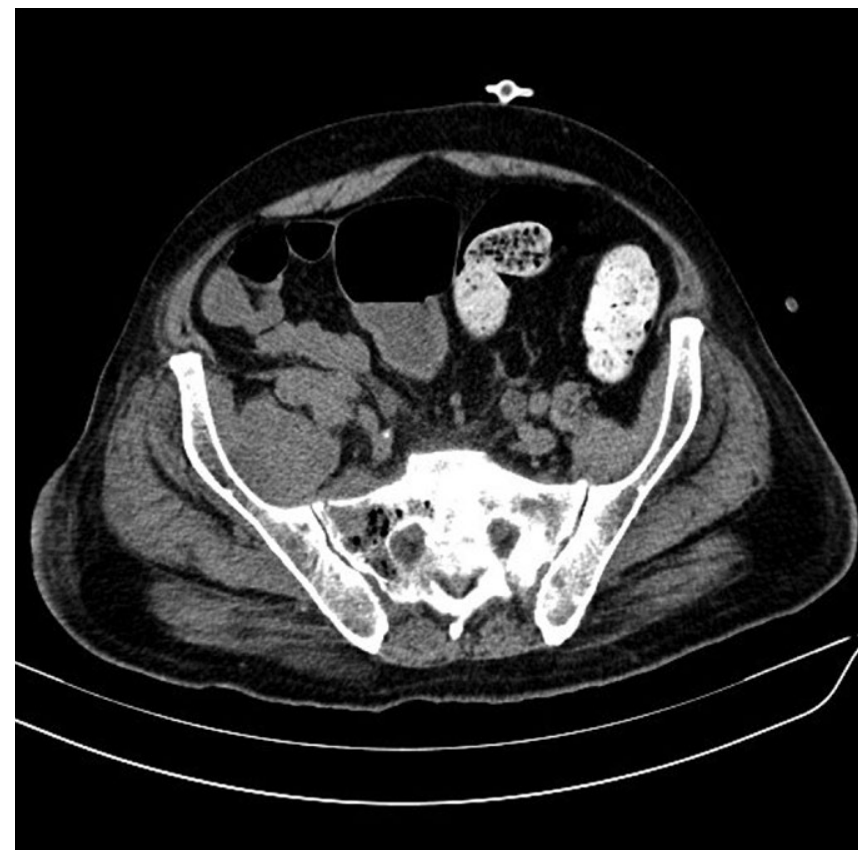

Figura 1: Osteomielite enfisematosa do sacro com presença de gás intraósseo em corte axial.

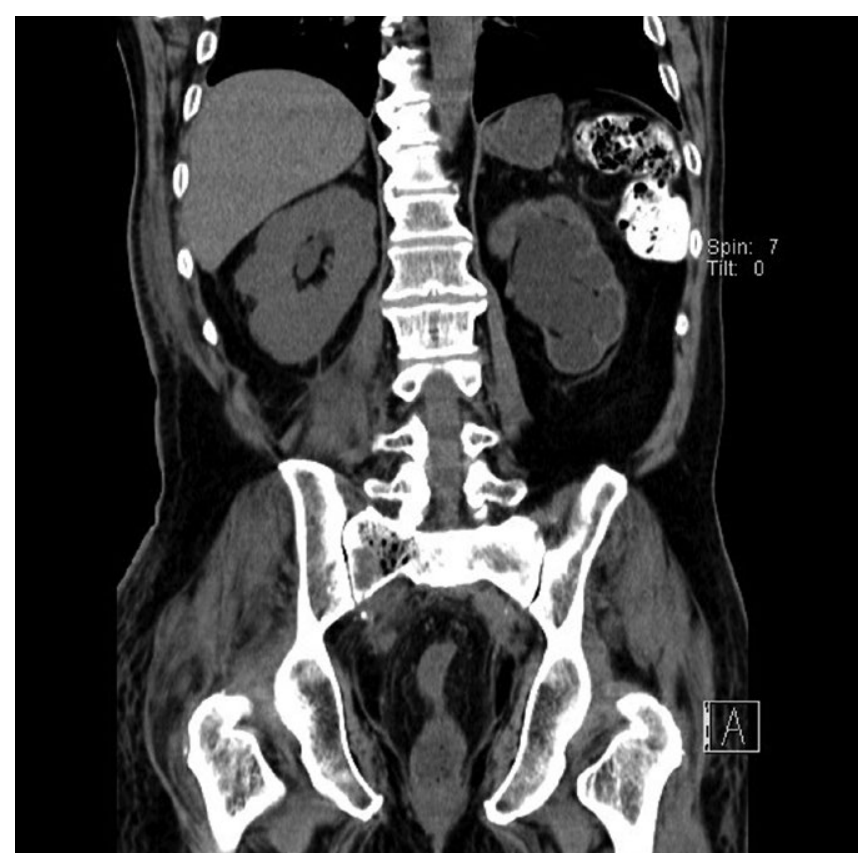

Figura 2: Osteomielite enfisematosa do sacro com presença de gás intraósseo em corte sagital. 
cirúrgico está reservado para os casos complicados de abcesso ou necrose, ,4,6 e associa-se a pior prognóstico. 2,6

Estão descritos cerca de 50 casos de OE na literatura inglesa. ${ }^{5}$ A OE apresenta uma elevada taxa de mortalidade, ${ }^{1,5}$ pelo que exige um diagnóstico precoce e tratamento agressivo.

\section{Responsabilidades Éticas}

Conflitos de Interesse: Os autores declaram a inexistência de conflitos de interesse na realização do presente trabalho.

Fontes de Financiamento: Não existiram fontes externas de financiamento para a realização deste artigo.

Confidencialidade dos Dados: Os autores declaram ter seguido os protocolos da sua instituição acerca da publicação dos dados de doentes. Consentimento: Consentimento do doente para publicação obtido. Proveniência e Revisão por Pares: Não comissionado; revisão externa por pares.

\section{Ethical Disclosures}

Conflicts of interest: The authors have no conflicts of interest to declare.

Financing Support: This work has not received any contribution, grant or scholarship

Confidentiality of Data: The authors declare that they have followed the protocols of their work center on the publication of data from patients.

Patient Consent: Consent for publication was obtained.

Provenance and Peer Review: Not commissioned; externally peer reviewed.

(c) Autor (es) (ou seu (s) empregador (es)) e Revista SPMI 2021. Reutilização permitida de acordo com CC BY-NC. Nenhuma reutilização comercial. (c) Author(s) (or their employer(s)) and SPMI Journal 2021. Re-use permitted under CC BY-NC. No commercial re-use.

\section{Correspondence / Correspondência:}

Andreia Machado Ribeiro - andreiammachadoribeiro@gmail.com Serviço de Medicina Interna, Hospital Vila Franca de Xira, Vila Franca de Xira, Portugal

Estrada Carlos Lima Costa No2, 2600-009 Vila Franca de Xira

Received / Recebido: 20/05/2021

Accepted / Aceite: 25/07/2021

Publicado / Published: 21/12/2021

\section{REFERÊNCIAS}

1. Mautone M, Gray J, Naidoo P. A case of emphysematous osteomyelitis of the midfoot: imaging findings and review of the literature. Case Rep Radiol. 2014;2014:616184. doi:10.1155/2014/616184.

2. Luey C, Tooley D, Briggs S. Emphysematous osteomyelitis: a case report and review of the literature. Int J Infect Dis. 2012;16:216-20. doi:10.1016/j. ijid.2011.11.007.

3. Kivrak A, Sumer S, Demir N, Aydin B. The life-saving little tip: intraosseous gas. BMJ Case Rep. 2013;2013:bcr2013201648. doi:10.1136/bcr-2013201648.

4. Lee J, Jeong C, Lee M, Jeong E, Kim Y, Kim S, et al. Emphysematous osteomyelitis due to Escherichia coli. J Infect Chemother. 2017;49:151-4. doi:10.3947/ic.2017.49.2.151.

5. Sulyma V, Sribniak A, Bihun R, Sribniak Z. Emphysematous osteomyelitis: review of the literature. Ortop Traumatol Reabil. 2020; 22: 153-9 doi: 10.5604/01.3001.0014.3231.

6. Mujer M, Rai M, Hassanein M, Mitra S. Emphysematous osteomyelitis. BMJ Case Rep. 2018;2018:bcr2018225144. doi:10.1136/bcr-2018-225144. 